\title{
Preliminary flight test correlations of the X-HALE aeroelastic experiment
}

\author{
J. R. Jones \\ jrenejo@umich.edu \\ C. E. S. Cesnik \\ cesnik@umich.edu \\ Department of Aerospace Engineering \\ University of Michigan \\ Michigan \\ USA
}

\section{ABSTRACT}

An experimental, remotely-piloted aircraft has been designed and fabricated at University of Michigan that is aeroelastically representative of very flexible aircraft. Known as X-HALE, this Experimental High-Altitude Long-Endurance aircraft exhibits geometrically nonlinear behaviour and displays specific aeroelastic characteristics designed into the experiment. This paper presents the data from the initial flight tests of the lightly instrumented X-HALE Risk Reduction Vehicle that confirm the expected aeroelastic characteristics. This opens the way for future flight tests with a fully-instrumented platform which will provide data to support validation of coupled, nonlinear aeroelastic/flight dynamic codes.

\subsection{INTRODUCTION}

In recent years, there has been a growing interest in the class of unmanned vehicle known as high altitude long endurance (HALE) aircraft. The mission profile of a HALE aircraft involves cruising at very high altitudes, and very-long endurance flights are highly desirable. The intended duration of these flights can be measured in days, weeks, and even months, rather than hours. The mission profile, similar to a very low-orbit satellite, is ideal for military applications, including airborne intelligence, surveillance, and reconnaissance purposes, as well as civilian uses, such as atmospheric research and communications networking. The requirements of HALE flight lead to vehicles characterised by low structural weight fraction and high lift-to-drag ratio. This translates to very lightweight designs with high-aspect-ratio wings, resulting in very flexible airframes. HALE designs have become so flexible that traditional, linear approaches to modeling their dynamic flight behaviour are insufficient. 
Zerweckh et $a l^{(1)}$ and van Schoor and von Flotow ${ }^{(2)}$ presented studies based on the flight tests of the ultra-light, human-powered Daedalus aircraft that demonstrated that the traditional approach of modeling rigid-body and flexible dynamics separately does not adequately capture the aircraft dynamics of very flexible aircraft. They concluded that flexibility of the aircraft structure as well as the full unsteady aerodyamic loads must be included in the flight dynamics model for the design and control of very flexible aircraft.

In more recent years, a number of unique approaches to modelling the dynamics of flexible aircraft

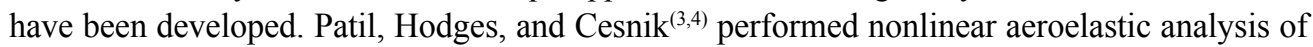
a Daedalus-based HALE aircraft using a geometrically-exact mixed-form beam formulation and unsteady, finite-state aerodynamics. Their study found that natural frequency, trim solution, and flight dynamic modes changed significantly as a function of tip displacement. Furthermore, stability analysis of the model performed using linear analysis methods yielded distinctly different results than the method that accounted for wing flexibility. After that, Patil and Hodges ${ }^{(5,6)}$ developed the Nonlinear Aeroelastic Trim and Stability of HALE Aircraft (NATASHA) analysis tool. It utilises in part the formulation developed in Refs 3,4 , but with a variation of the geometric nonlinear formulation in a fully intrinsic form. The formulation is coupled with $2 \mathrm{D}$ finite state unsteady aerodynamic loads to yield the nonlinear aeroelastic equations of motion. In parallel, Cesnik and co-workers ${ }^{(7,8)}$ developed the University of Michigan Nonlinear Aeroelastic Simulation Toolbox (UM/NAST), a time-domain nonlinear aeroelastic formulation that uses a strain-based, geometrically nonlinear beam model coupled with 2D finite state unsteady aerodynamic loads to simulate the aeroelastic behaviour of various aircraft configurations. UM/NAST's capabilities include fully nonlinear trim, steady state, and dynamic solutions, as well as linearised stability analysis for conventional aircraft, flying wings and joined wing aircraft ${ }^{(9)}$. A similar approach to the problem was taken by Drela's integrated simulation method ${ }^{(10)}$. It modelled the structural dynamics of very flexible aircraft using a nonlinear displacement-based beam formulation to capture arbitrarily large deformations. Coupled with an unsteady vortex/source-lattice method, this approach generated frequency-domain solutions to the aeroelastic equations of motion. Modal analysis using this method also showed that the structural and flight dynamic modes of very flexible aircraft (VFA) were no longer distinct and easily correlatable with the rigid-body modes of traditional fixed wing aircraft. More recently, Palacios and co-workers ${ }^{(11)}$ compared generalised versions of several published formulations for structural and aerodynamic solvers. They found that the intrinsic- and strain-based formulations outperformed traditional displacement based solvers in terms of computational efficiency as well as overall effectiveness in capturing the geometrically nonlinear structural behaviour of flexible flying-wing type aircraft.

In 2003, a spotlight was thrown on the aeroelastic modelling community when the Helios, a NASA-Aerovironment prototype high-altitude long-endurance aircraft was destroyed during an endurance test flight. To advance the understanding of the behaviour of very flexible aircraft and prevent future mishaps, NASA's mishap report ${ }^{(12)}$ made the following recommendation:

Develop more advanced, multidisciplinary ... 'time-domain' analysis methods appropriate to highly flexible, 'morphing'vehicles. Develop ground-test procedures and techniques appropriate to this class of vehicle to validate new analysis methods and predictions.

Attempts to validate those coupled, nonlinear aeroelastic solvers and evaluate their usefulness in the design and analysis of VFA have been made using the limited set of experimental data available for the different components of the analysis, including bench tests, wind tunnel tests, and data from validated linear aeroelastic solvers (e.g., NASTRAN $)^{(13-15)}$. However, no fully coupled nonlinear aeroelasticity/flight dynamics experimental data exists in the public domain that could be used for the validation of integrated formulations for analysis and design of VFA. 


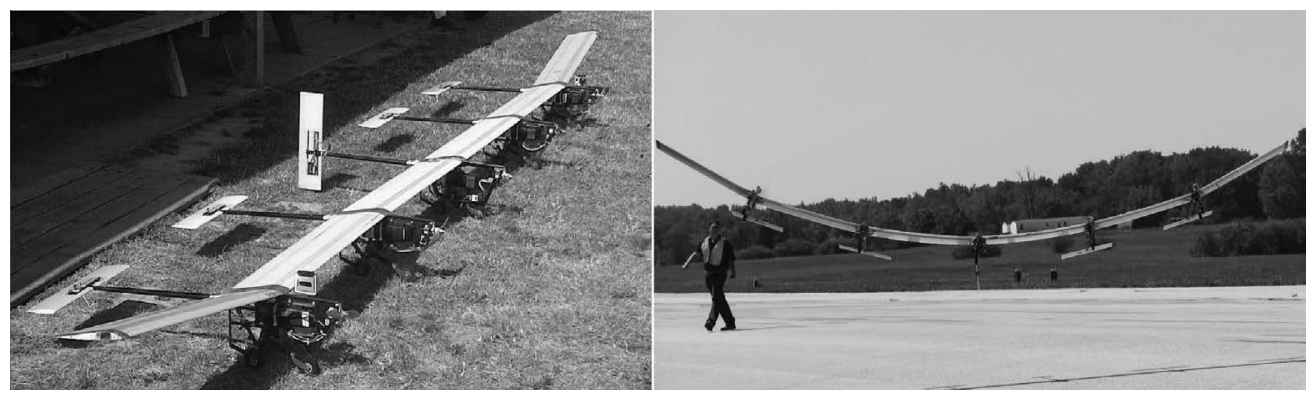

Figure 1. X-HALE risk reduction vehicle on the ground (left) and in flight (right).

To that end, the University of Michigan's experimental high-altitude long-endurance (X-HALE) experiment is an attempt to address the need for relevant aeroelastic data to support validation of nonlinear aeroelastic solvers ${ }^{(16)}$. This paper gives a brief overview of the design and fabrication of the X-HALE airframe and a description of the test conditions and data gathered during flight tests. Finally, correlations between the limited set of test flight data and the UM/NAST simulations are presented.

\subsection{OVERVIEW OF THE X-HALE RISK REDUCTION VEHICLE (RRV)}

Using UM/NAST, an experiment (X-HALE) in the form of a remotely piloted aircraft was designed so to be:

- aeroelastically respresentative of VFA aircraft, represented by coupling between the rigid body and flexible states;

- linearly stable under trimmed flight with enough control authority to excite various nonlinear vehicle responses; and

- capable of static wing deformations with tip deflection greater than $30 \%$ of the semispan.

The design also presents an unstable (but controllable) Dutch-roll coupled first wing bending mode when subjected to large disturbances. This lateral behaviour would have been very difficult to test in a wind tunnel environment. The choice of construction, materials, and geometry were such that they allow accurate characterisation of the stiffness and inertia properties of the aircraft. Detailed description of the design is presented in Ref. 16.

As a risk reduction path for developing a fully instrumented X-HALE, multiple vehicles were conceived with various levels of instrumentation. The primary purpose of the X-HALE Risk Reduction Vehicle (RRV), shown in Fig. 1, is to verify the aeroelastic properties of the airframe design and and its overall behaviour in flight before a fully instrumented X-HALE Aeroelastic Test Vehicle (ATV) could be manufactured. This paper concentrates on the RRV test flight results, and attempts a preliminary data comparison with UM/NAST simulations, even though the aircraft was not instrumented for high-quality data capture. 


\section{Table 1 \\ Main airframe characteristics of the X-HALE RRV}

$\begin{array}{lll}\text { Wing span } & 6 & \mathrm{~m} \\ \text { Wing chord } & 0 \cdot 2 & \mathrm{~m} \\ \text { Planform area } & 1 \cdot 2 & \mathrm{~m}^{2} \\ \text { Aspect ratio } & 15 & - \\ \text { Length } & 0 \cdot 96 & \mathrm{~m} \\ \text { Propeller diameter } & 0 \cdot 30 & \mathrm{~m} \\ \text { Max gross take-off weight } & 10 \cdot 9 & \mathrm{~kg} \\ \text { C.G. (w.r.t leading edge) } & 32 \cdot 6 & \% \text { wing chord } \\ \text { Power/weight } & 10 \cdot 73 & \mathrm{~W} / \mathrm{kg} \\ \text { Airspeed range } & 10-20 & \mathrm{~ms}^{-1}\end{array}$

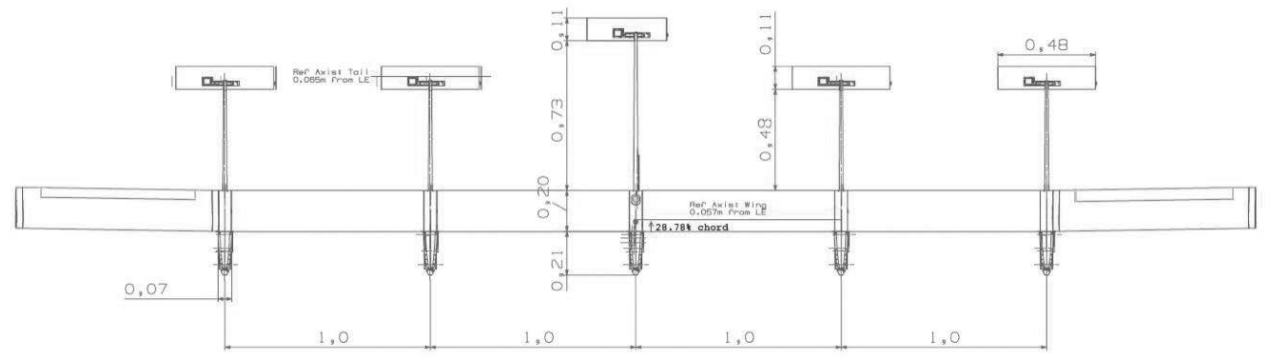

Figure 2. Layout of the X-HALE Risk Reduction Vehicle.

\subsection{RRV airframe properties}

The X-HALE RRV is a flexible, high-aspect-ratio wing-boom-tail type aircraft. It has a $6 \mathrm{~m}$ wingspan constructed from six identical $1 \mathrm{~m}$ wing segments with $0 \cdot 2 \mathrm{~m}$ chord. The wing tip segments are mounted with a 10-degree dihedral to augment the lateral stability of the aircraft. Five pods are evenly distributed along the wingspan, containing electric motors, batteries, and the payload, which is described further in Section 2.2. Attached to these pods were originally five $0.65 \mathrm{~m}$ booms with $0 \cdot 12 \mathrm{~m}$-chord horizontal tails. Exploratory flight trials showed that the aircraft was not controllable with the tail boom configuration described in Ref. 17. A longer centre tail boom and ventral fins on the centre tail and two adjacent ones were added for additional yaw damping during flight. Due to the larger moment arm introduced by the longer boom, a simple tail bracing system, consisting of high strength Kevlar wire, was implemented to stiffen the centre pod-tail-boom assembly.

The main airframe characteristics of the X-HALE RRV are summarised in Table 1. A basic dimensioned drawing of the RRV is shown in Fig. 2. The X-HALE RRV with elongated centre tail and ventral fins is shown during takeoff in Fig. 3.

The airframe structure is fabricated primarily from composite materials to minimise the structural weight. The wings are fabricated using fibreglass/epoxy, reinforced at each end with graphite/ epoxy, and supported by aerodynamically shaped low-density, high-strength structural foam. The pods are assembled from a central graphite/epoxy spine to which the motor, batteries, and all 


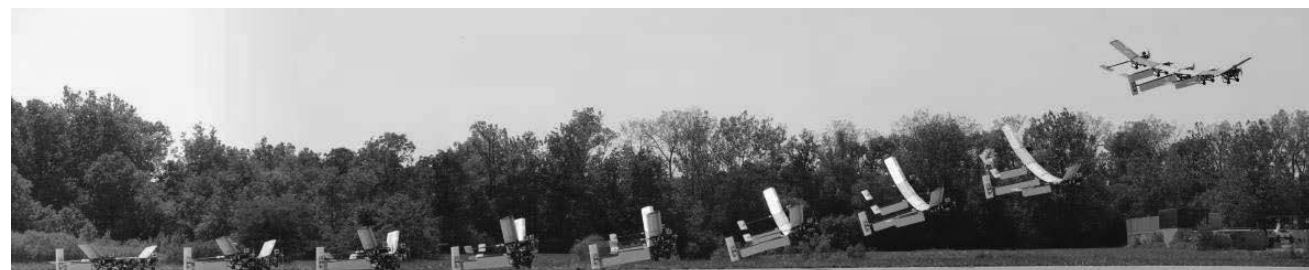

Figure 3. X-HALE RRV with elongated centre tail and ventral fins showing large wing deflections during take-off.

\section{Table 2}

\section{List of the component properties of the X-HALE RRV model}

$\begin{array}{lcccccc} & \text { Wing } & \text { Boom } & \text { Tail } & \text { Pod } & \text { Fin } & \text { Units } \\ \text { Ref. axis location (from L.E.) } & 28 \cdot 8 & 40 \cdot 9 & 32 \cdot 4 & 60 \cdot 9 & 50 \cdot 0 & \% \text { chord } \\ \text { Centre of gravity (from L.E.) } & 25 & 40 \cdot 9 & 25 \cdot 0 & 25 \cdot 0 & 50 \cdot 0 & \% \text { chord } \\ \text { Incidence angle } & 5 & \mathrm{n} / \mathrm{a} & 0 & 0 & 0 & \text { deg } \\ \text { Chord length / diameter } & 0 \cdot 20 & 0 \cdot 024(\mathrm{f})^{(1)} & 0 \cdot 11 & 0 \cdot 37 & 0 \cdot 73(\mathrm{c})^{(2)} & \mathrm{m} \\ & & 0 \cdot 013(\mathrm{r}) & & & 0 \cdot 485(\mathrm{o}) & \\ & 0 \cdot 394 & 0 \cdot 0429 & 0 \cdot 2614 & - & 0 \cdot 239 & \mathrm{~kg} / \mathrm{m} \\ \text { Mass per unit span (m) } & 8 \cdot 09 \times 10^{-4} & 2 \cdot 91 \times 10^{-4} & 1 \cdot 60 \times 10^{-4} & - & 1 \cdot 81 \times 10^{-2} & \mathrm{~kg}-\mathrm{m}^{2} \\ \text { Rotation inertia }\left(I_{x x}\right) & 1 \cdot 22 \times 10^{-5} & 1 \cdot 46 \times 10^{-9} & 2 \cdot 91 \times 10^{-6} & - & 5 \cdot 58 \times 10^{-4} & \mathrm{~kg}-\mathrm{m}^{2} \\ \text { Out-plane bend. Inertia }\left(I_{y y}\right) & -6 \cdot 49 \times 10^{-4} & 0 & 0 & - & 0 & \mathrm{~kg}-\mathrm{m}^{2} \\ \text { Out/In-plane bend. Inertia }\left(I_{y z}\right) & 7 \cdot 97 \times 10^{-4} & 1 \cdot 46 \times 10^{-9} & 1 \cdot 57 \times 10^{-4} & - & 1 \cdot 75 \times 10^{-2} & \mathrm{~kg}-\mathrm{m}^{2} \\ \text { In-plane bending inertia }\left(I_{z z}\right) & 2 \cdot 14 \times 10^{6} & - & - & - & - & \mathrm{N} / \mathrm{m}^{2} \\ \text { Extensional stiffness }\left(k_{11}\right) & 1 \cdot 54 \times 10^{3} & - & - & - & - & \mathrm{N} / \mathrm{m}^{2} \\ \text { Ext./Out-plane bend. Stiffness }\left(k_{13}\right) & -4.91 \times 10^{4} & - & - & - & - & \mathrm{N} / \mathrm{m}^{2} \\ \text { Ext./In-plane bend. Stiffness }\left(k_{14}\right) & 55 \cdot 8 & - & - & - & - & \mathrm{N} / \mathrm{m}^{2} \\ \text { Torsional stiffness }\left(k_{22}\right) & 1 \cdot 04 \times 10^{2} & - & - & - & - & \mathrm{N} / \mathrm{m}^{2} \\ \text { Out-plane bend. Stiffness }\left(k_{33}\right) & -46 \cdot 34 & - & - & - & - & \mathrm{N} / \mathrm{m}^{2} \\ \text { Out/In-plane bend. Stiffness }\left(k_{34}\right) & 6 \cdot 35 \times 10^{3} & - & - & - & - & \mathrm{N} / \mathrm{m}^{2} \\ \text { In-plane bend. Stiffness }\left(k_{44}\right) & & & & & & \end{array}$

payload components are mounted. A moulded fibreglass skin is used to provide an aerodynamic surface to the flow over the pods as well as protect the spine-mounted electronics although they were not used for the flights described here. The individual wing segments are connected to each other by precisely machined, lightweight aluminium joiners that transmit bending and torsion loads uniformly from spar to spar.

The properties of the X-HALE components are summarised in Table 2 and Table 3 and are referenced to the local reference co-ordinate frame. The origin of each local reference axes is given in the Table 2, and the $x, y, z$ axes point towards the right main wingtip, the wing leading edge, and vertically, respectively. Table 2 details the geometry and cross-sectional inertias of the primary aircraft structure, as well as the elements of the wing stiffness matrix. Table 3 lists properties of the concentrated inertias used to model additional aircraft components. 


\section{Table 3}

\section{List of the concentrated inertias of the X-HALE RRV model}

\begin{tabular}{lcc} 
& \multicolumn{2}{c}{ Inboard pods } \\
& Payload & $\begin{array}{c}\text { Pod } \\
\text { assembly }\end{array}$ \\
Mass & 0.548 & 0.929 \\
$x_{c g}$ & 0.01 & $2.14 \times 10^{-3}$ \\
$y_{c g}$ & 0.09 & $4.0 \times 10^{-2}$ \\
$z_{c g}$ & 0 & $7.81 \times 10^{-2}$ \\
$I_{x x}$ & $9 \cdot 13 \times 10^{-4}$ & $1.134 \times 10^{-2}$ \\
$I_{y y}$ & $4.57 \times 10^{-4}$ & $3.21 \times 10^{-3}$ \\
$I_{z z}$ & $4.57 \times 10^{-4}$ & $8.48 \times 10^{-3}$ \\
$I_{x y}$ & 0 & $-1.21 \times 10^{-3}$ \\
$I_{x z}$ & 0 & $1.06 \times 10^{-5}$ \\
$I_{y z}$ & 0 & $4.59 \times 10^{-5}$
\end{tabular}

\section{Outboard pods \\ Payload \\ Pod assembly}

0.571

0.010

0.0941

0

$9.52 \times 10^{-4}$

$4.76 \times 10^{-4}$

$4.67 \times 10^{-4}$

0

0

0

1.046
$3.97 \times 10^{-3}$
$6 \cdot 12 \times 10^{-2}$
$7.52 \times 10^{-2}$
$1.134 \times 10^{-2}$
$3.21 \times 10^{-3}$
$8.48 \times 10^{-3}$
$-1.21 \times 10^{-3}$
$1.06 \times 10^{-5}$
$4.59 \times 10^{-5}$

Centre pod

Payload $\begin{gathered}\text { Pod } \\ \text { assembly }\end{gathered}$

Units

$$
0 \cdot 375
$$

0

$0 \cdot 1$

0

$6 \cdot 24 \times 10^{-4}$

$3 \cdot 12 \times 10^{-4}$

$3 \cdot 12 \times 10^{-4}$

0

0

0 $\begin{array}{cc}1.046 & \mathrm{~kg} \\ 3.97 \times 10^{-3} & \mathrm{~m}\end{array}$

$6.12 \times 10^{-2} \quad \mathrm{~m}$

$7.52 \times 10^{-2} \quad \mathrm{~m}$

$1.476 \times 10^{-2} \quad \mathrm{~kg}-\mathrm{m}^{2}$

$2.82 \times 10^{-3} \quad \mathrm{~kg}-\mathrm{m}^{2}$

$2.50 \times 10^{-4} \quad \mathrm{~kg}-\mathrm{m}^{2}$

$2 \cdot 32 \times 1^{-4} \quad \mathrm{~kg}-\mathrm{m}^{2}$

$2.27 \times 1^{-3} \quad \mathrm{~kg}-\mathrm{m}^{2}$

$4.50 \times 10^{-4} \quad \mathrm{~kg}-\mathrm{m}^{2}$

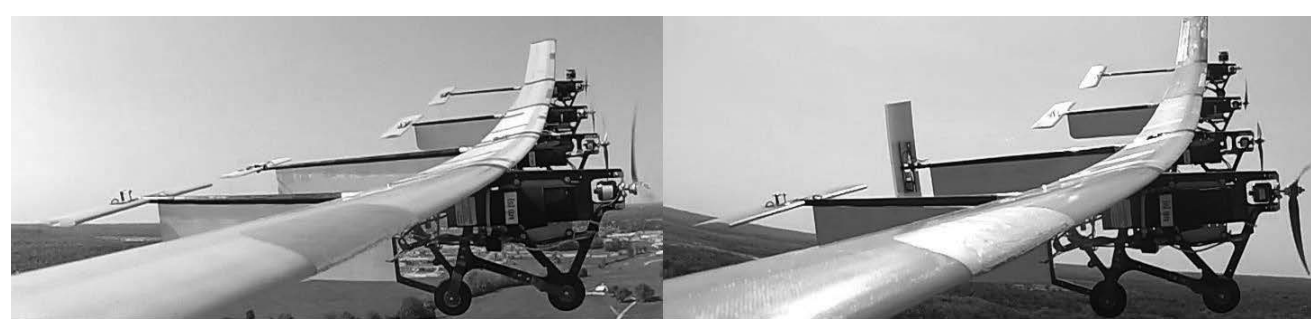

Figure 4. X-HALE RRV with centre tail in horizontal $(I)$ and vertical ( $r$ ) configurations during flight.

\subsection{FLIGHT CONTROL AND SENSOR SYSTEM}

Control authority of X-HALE RRV is maintained by radio-controlled servo actuators. Five motors evenly distributed along the wingspan of the X-HALE RRV provide forward thrust as well as directional control via differential thrust, i.e., a left turn is commanded by increasing power to the right outboard motor while decreasing power to the left outboard motor. The four horizontal tails situated aft of each outboard pod provide elevator pitch control for take-off, climbing, and descent manoeuvres. The centre tail, shown in Fig. 4, rotates discretely between horizontal and vertical positions as needed to increase the airframe's lateral damping and arrest the excited Dutch-roll/wing bending mode ${ }^{(17)}$. Ailerons located in the centre of the dihedral wing segments are used to introduce disturbances to the trimmed vehicle and simulate gust excitation. They are not used for flight control.

The X-HALE RRV is radio-controlled using a nine-channel $2.4 \mathrm{GHz}$ transmitter and receiver system. The aircraft is equipped with an Eagletree telemetry data logging system. This system records the servo pulse width modulation (PWM) commanded by the pilot, and the GPS position, speed, and aircraft heading. Selected sensor readings, including speed and altitude, are transmitted in real time to a handheld wireless display to aid the test team in decision-making during the flight.

In addition to the data recorded by the Eagletree system, the X-HALE RRV is outfitted with two other sources of data capturing. Each motor is equipped with a 50W Castlelink electronic speed 


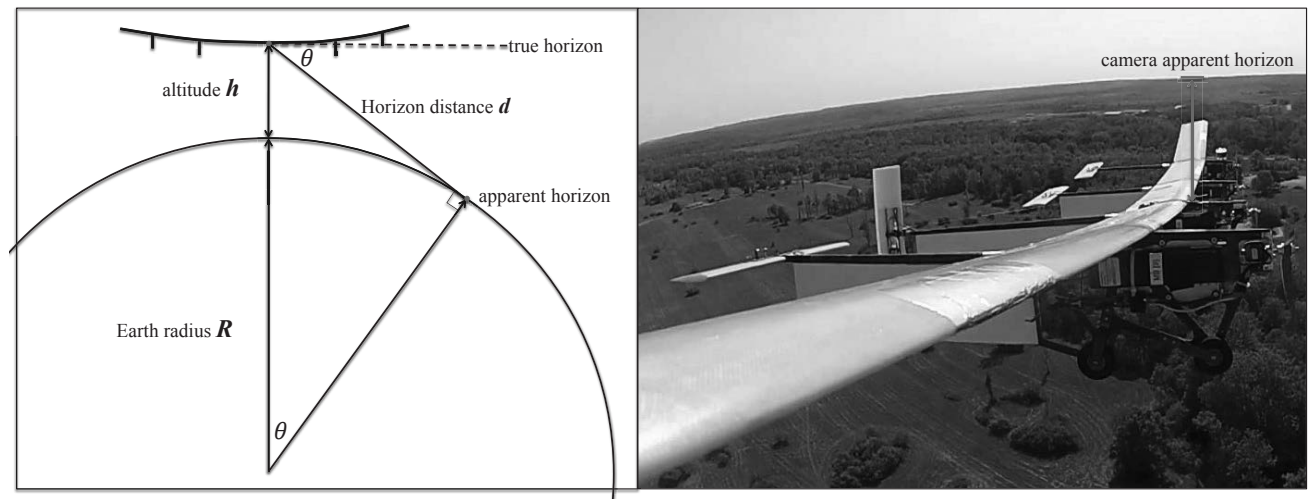

Figure 5. Diagram of aircraft-horizon geometry.

controller that regulates and records motor shaft rpm, temperature, battery voltage, input current, and commanded power levels as a percentage of maximum motor output. Two centre-facing GoPro Hero 2 cameras are installed in the outboard spines to record the motion of the aircraft during flight. Moreover, team members on the ground also record high definition video of the flight in an attempt to capture different aspects of vehicle flight behaviour.

\subsubsection{Determining aircraft Euler angle response}

As discussed above, the X-HALE RRV was not intended for aeroelastic tests, and, therefore, did not carry the instrumentation needed to directly collect flight mechanics and/or aeroelastic data. However, an attempt to estimate vehicle attitude is made here with the available collected data. The post-processing of the onboard camera footage provides close estimates of the roll angle relative to the horizon and the aircraft body angle-of-attack. Figure 5 shows the geometry of the horizon relative to the aircraft location. The location of the horizon in the image recorded by the onboard cameras is known as the apparent horizon. If $R$ is the radius of the earth, and $h$ is the altitude of the aircraft above the earth's surface, then:

$$
\begin{gathered}
a=\sqrt{(R+h)^{2}-R^{2}} \\
\theta=\operatorname{Tan}^{-1}\left(\frac{d}{R}\right)
\end{gathered}
$$

where $d$ is the horizon distance and $\theta$ is the angle of the apparent horizon below the camera's true horizon.

Using an image captured at the altitude of interest when the aircraft is flying with wings level, the position of the horizon in the camera field of view (FOV) can also be measured in pixels. From this measurement, the ratio of horizon angle $\theta$ to image pixels for the camera used can be calculated. Using this ratio, the position of the horizon in each camera frame can be used to approximate the aircraft roll angle. The aircraft pitch angle can be approximated by comparing the angle of the apparent horizon in the camera FOV with a horizontal reference. Vertical wingtip displacement is approximated by measuring the wingtip position in pixels relative to the centre of the aircraft for each camera frame. This measurement is then normalised against the wing position within the initial frame. 


\section{Table 4 \\ Flight conditions at airfield for X-HALE RRV test flight}

Temperature

Wind direction and speed

Precipitation

Cloud cover

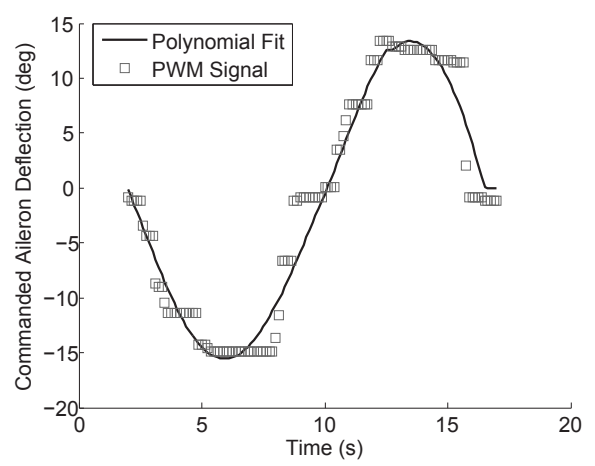

Figure 6. Flight test excitation - aileron input 1 (A1). $78^{\circ} \mathrm{F}$

090 at $5 \mathrm{mph}$

None

Clear

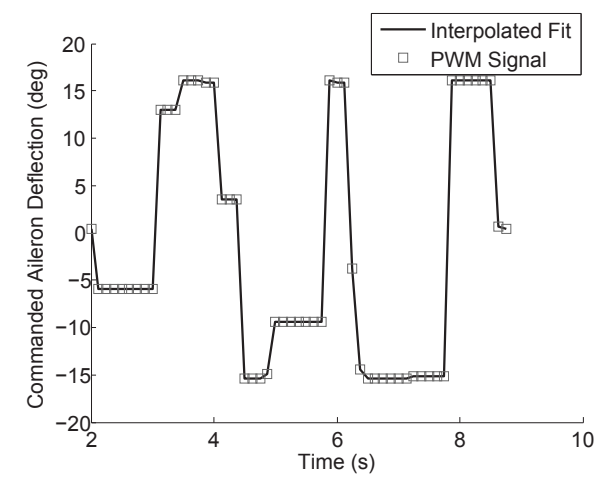

Figure 7. Flight test excitation - aileron input 2 (A2).

\subsection{FLIGHT TEST RESULTS AND CORRELATIONS WITH UM/NAST}

\subsection{X-HALE RRV flight test results}

The goal of the initial flight of the RRV was to establish the controllability and handling qualities of the airframe. As expected, the elongated centre tail and ventral fins succeeded in damping the lateral instability present in exploratory flight trials, allowing the pilot to complete several righthanded racetrack manoeuvres with minimal retrimming of the aircraft. The aircraft completed a successful runway landing, with a total flight time of 6 minutes, 10 seconds. The X-HALE RRV flight was conducted when conditions at the field were as given in Table 4.

A second flight with the same configuration was flown under similar weather conditions. The objective of this flight was to confirm that the airframe exhibited the predicted aeroelastic characteristics, including large tip deflection and coupled structural and flight dynamic behaviour. During this flight, two aileron inputs were given to the aircraft to simulate gust-like excitations. The first aileron input (A1), commanded while the aircraft was in a vertical centre tail configuration, is shown in Fig. 6. A second aileron input (A2) was commanded with the aircraft in the marginally stable horizontal centre-tail configuration. This higher frequency input, shown in Fig. 7, was an attempt to excite the unstable dutch roll coupled with first bending modes observed in simulations $^{(3,4)}$ and in exploratory flight trials. A polynomial (cubic) curve fit of aileron input 1 (A1) was used in Fig. 6 for the UM/NAST simulation to avoid higher frequency excitation as result of the noise in the experimental signal. Similarly, linear interpolation was used to represent aileron input 2 (A2) when applied to the simulation model. 

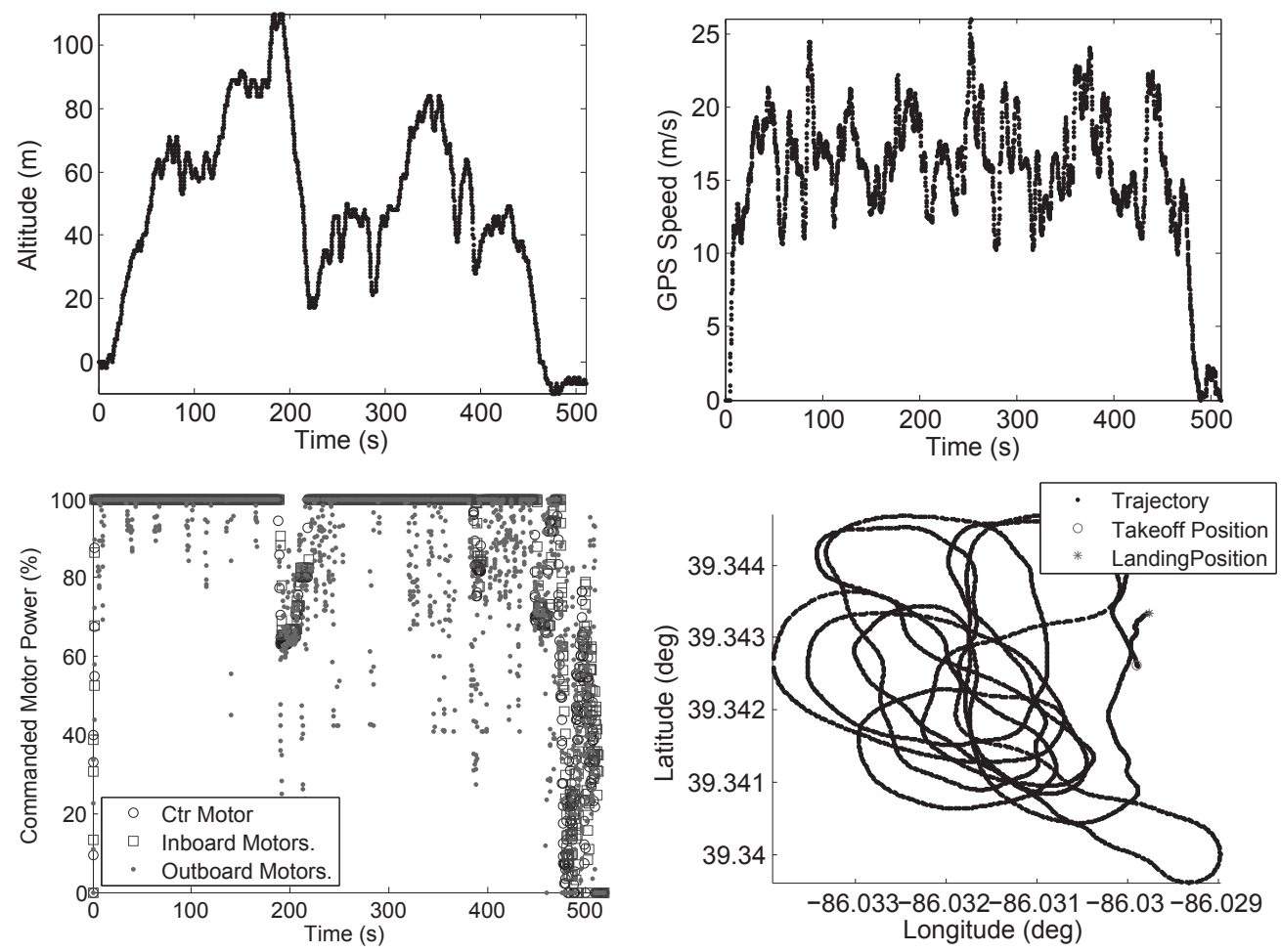

Figure 8. Top - Altitude (I) and ground speed (r); Bottom - Percent motor power (I) and GPS trajectory ( $r$ ) for the duration of the second flight.

The flight ended with another successful runway landing, with a total flight time of 8 minutes and 25 seconds from takeoff to landing. The data recorded for the duration of the second flight test is shown in Fig. 8.

\subsection{X-HALE RRV simulation parameters}

A model of the X-HALE RRV was created for UM/NAST from the properties of the assembled aircraft and its components, described previously in Table 2 and Table 3. The wings were modelled as fully flexible members while the pods, tail booms, ventral fins, and tails were treated as rigid components. The thrust of each motor was modelled as a time-dependent, body-fixed force acting at the pod locations. The elevators and centre tail were modelled as fully movable control surfaces with degrees of freedom in pitch and roll directions, respectively. The ailerons were modeled as traditional, trailing-edge control surfaces. The trim solution of the model was generated using only motor thrust and elevator angle as control inputs, as the ailerons are not used for trimming the aircraft during flight.

For this configuration the trim solution body angle-of-attack, elevator angle, and motor thrust were calculated in UM/NAST at the instantaneous flight speed immediately before the aileron inputs were applied. The corresponding trimmed static tip deflection is also calculated. The results are summarised in Table 5. 


\section{Table 5 X-HALE RRV trim parameters}

\author{
Trimmed parameter \\ Flight speed \\ Body angle-of-attack \\ Elevator deflection angle \\ Motor thrust \\ Static tip deflection
}

\author{
Value (unit) for A1 \\ $17.6\left(\mathrm{~ms}^{-1}\right)$ \\ $-1.25(\mathrm{deg})$ \\ $2.59(\mathrm{deg})$ \\ $1.69(\mathrm{~N})$ \\ $0.252(\mathrm{~m})$
}

\author{
Value (unit) for $\mathrm{A2}$ \\ $16.0\left(\mathrm{~ms}^{-1}\right)$ \\ $-0 \cdot 16(\mathrm{deg})$ \\ $1.77(\mathrm{deg})$ \\ $1.52(\mathrm{~N})$ \\ $0.253(\mathrm{~m})$
}

For the dynamic, time-marching simulation, the amplitude, duration, and frequency of the disturbance inputs commanded during the test flight, (i.e., inputs A1 and A2) were modelled with a polynomial curve fitted to the original PWM signal. The motors and elevators were set to their trimmed value and did not change from this constant setting during the aileron excitation. The following section describes the results of these simulations and compares them to the data gathered during the test flights.

\subsection{X-HALE RRV simulation and flight test correlations}

The University of Michigan Nonlinear Aeroelastic Simulation Toolbox is used to simulate the aircraft response to the inputs described in the previous section and the results are compared to the available flight data.

The simulated vertical displacement of the aircraft body frame from its initial position is compared to the measured GPS altitude. The magnitude of the body frame speed is compared to the measured GPS speed. The UM/NAST simulation assumes zero wind-speed, so the UM/NAST modeled airspeed and ground speed are identical, and direct comparison to the GPS speed are made without correcting for wind effects. The simulated yaw angle of the aircraft body frame relative to its initial orientation is compared to the measured GPS heading angle. The simulated roll and pitch angles are compared against estimates of the aircraft roll angle and pitch angle made from post-processing of the onboard camera data. The simulated and estimated wingtip displacement are normalised with respect to the initial wingtip positions.

Comparisons between the simulation results and experimental data for input A1 are shown in Figs 8-13. The aircraft is modelled in the vertical centre tail configuration using the parameters described previously.

The simulated RRV response to input A1 is more pronounced than the response seen in flight. In particular, the duration of the input yields an extremely high amplitude roll (Fig. 12) and pitch (Fig. 13) responses in the simulation, while the actual aircraft exhibited much calmer Dutch-roll-like behaviour that damped out within two cycles without pilot intervention due to the combined restoring forces of the ventral fins and vertically positioned centre tail. Conversely, the simulated wingtip deflection (Fig. 14) decreases from the initial value for the majority of the input, while the wingtip displacement measured during actual flight oscillated between the initial position and a high-dihedral configuration. When comparing the basic altitude (Fig. 9) and speed (Fig. 10) trends between the simulation and actual flight, there are significant discrepancies, showing opositive behaviour in some of the time segments. This clearly indicates that some of the input parameters in the simulation are not representative of the experiment. Unfortunately, due to the limited instrumentation, no further improvement can be made for this case. 


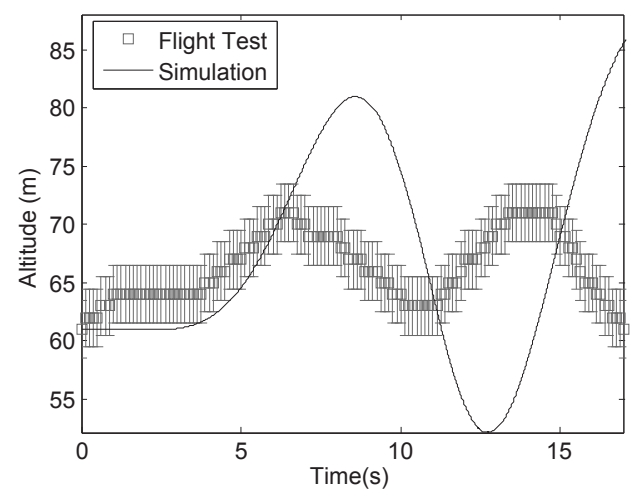

Figure 9. Comparison of simulated and measured altitude for input $\mathrm{A} 1$.

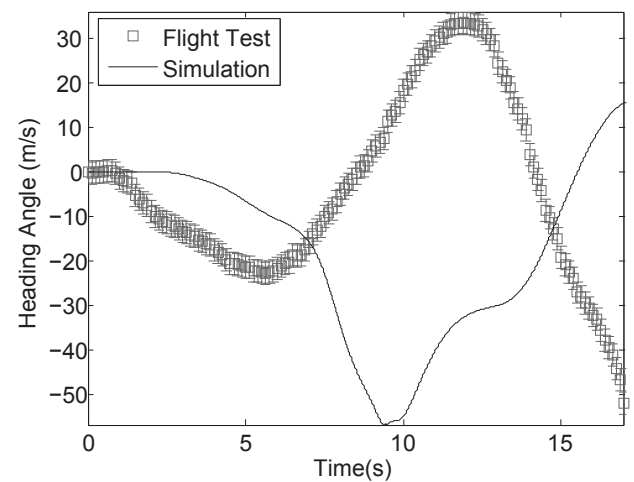

Figure 11. Comparison of simulated and measured heading angle for input $\mathrm{A} 1$.

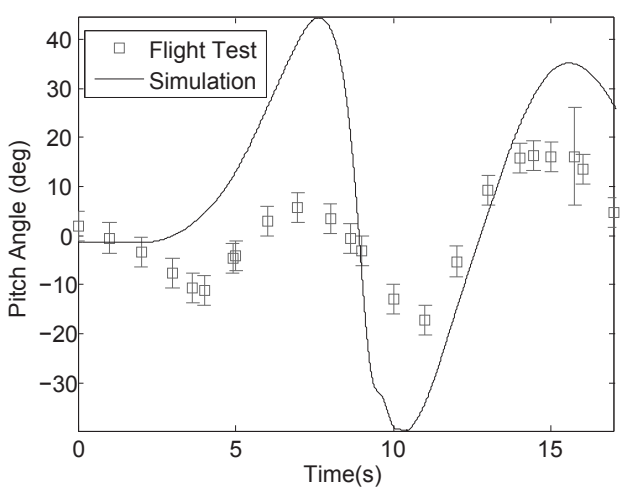

Figure 13. Comparison of simulated and estimated pitch angle for input $\mathrm{A} 1$.

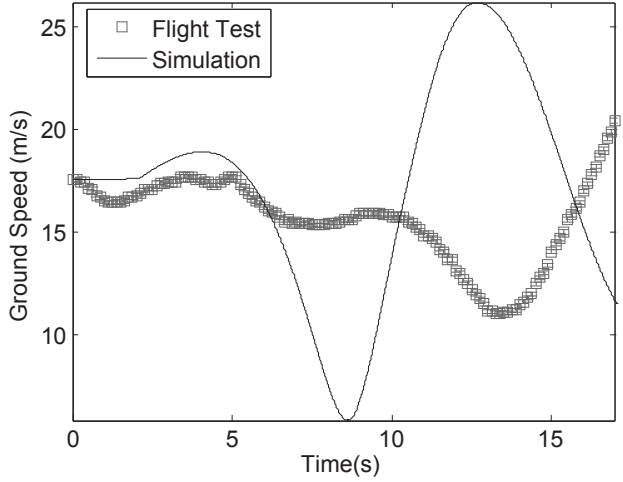

Figure 10. Comparison of simulated and measured speed for input $\mathrm{A} 1$.

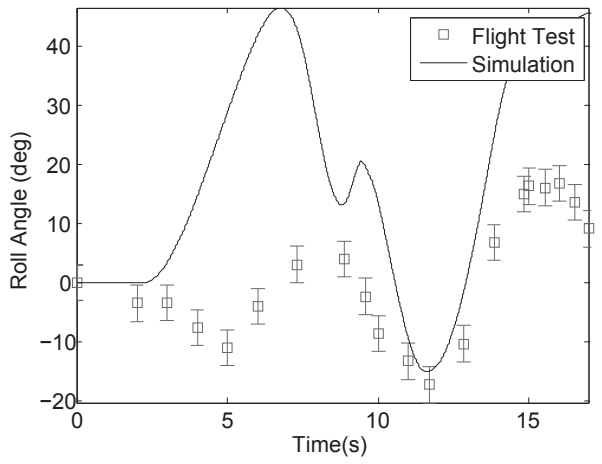

Figure 12. Comparison of simulated and estimated roll angle for input A1.

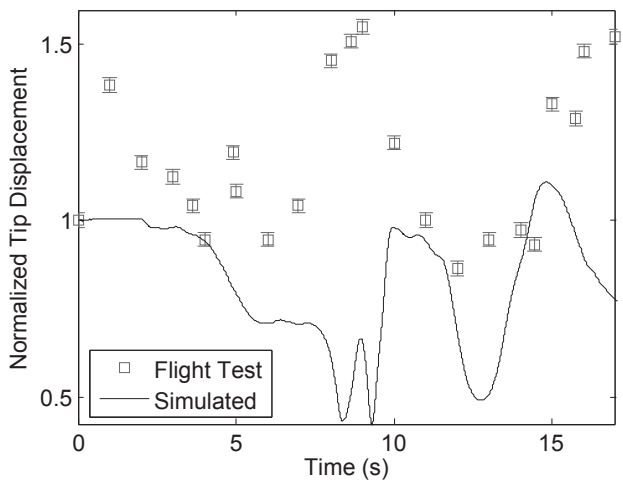

Figure 14. Comparison of simulated and estimated tip displacement for input A1. 




Figure 15. Comparison of simulated and measured altitude for input A2.

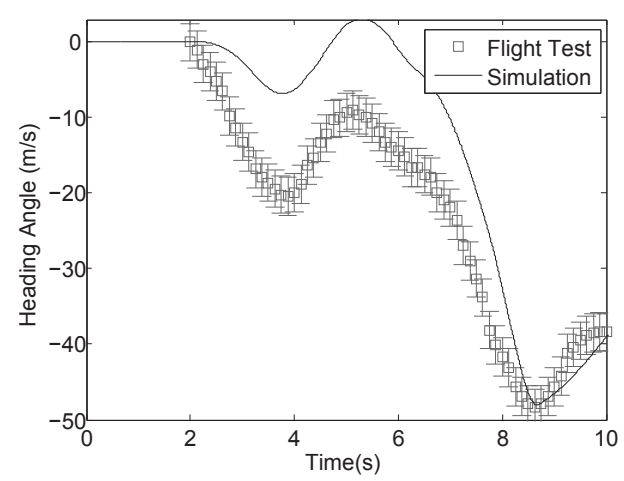

Figure 17. Comparison of simulated and measured heading angle for input A2.

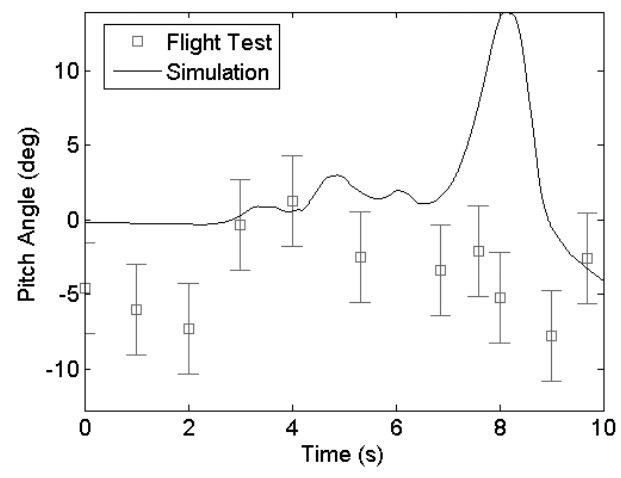

Figure 19. Comparison of simulated and estimated pitch angle for input $\mathrm{A} 2$.

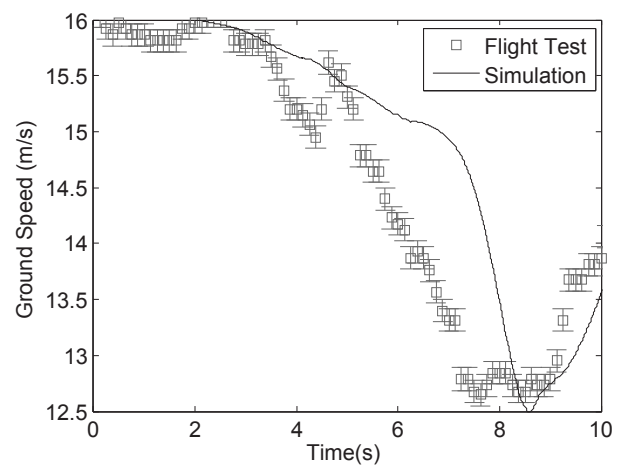

Figure 16. Comparison of simulated and measured speed for input A2.

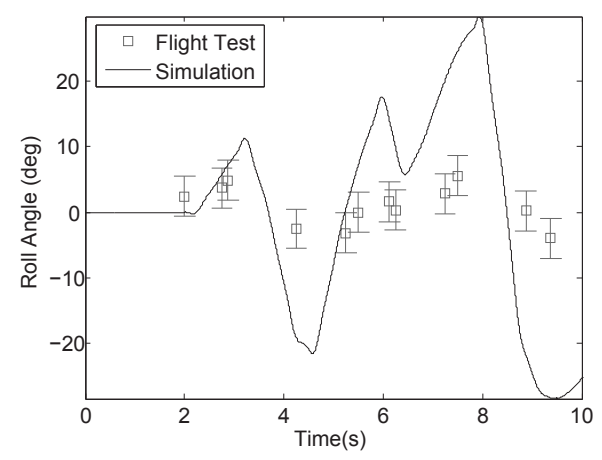

Figure 18. Comparison of simulated and estimated roll angle for input A2.

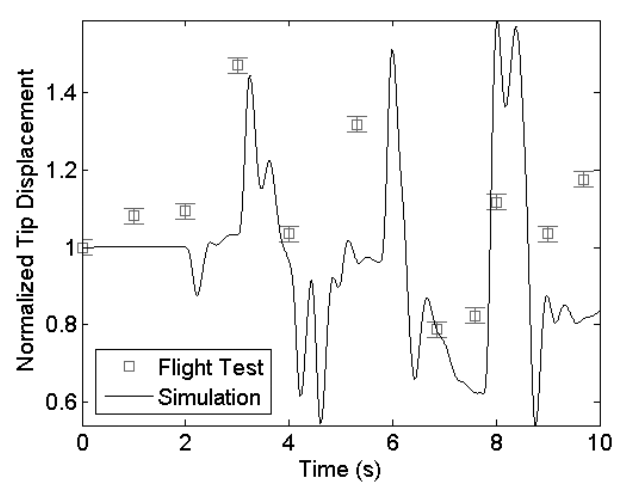

Figure 20. Comparison of simulated and estimated tip displacement for input A2. 
Comparisons between the simulation results and experimental data for input A2 are shown in Figs 15-20. The aircraft is modelled in the horizontal centre tail configuration using the parameters described previously.

The RRV's altitude and speed responses to the input A2, shown in Figs 15 and 16, are very close to the corresponding simulated ones. After the input, the RRV began to exhibit Dutch-roll-like coupling between the yaw angle and excited roll motion. After several seconds, the pilot had to inititate a turn to avoid crossing an airfield boundary. The pilot flipped the tail to its vertical position, and the immediate increase in the lateral stability of the aircraft arrested the coupled oscillatory motion. Both simulation and experiment reinforce this behaviour: in the absence of additional inputs, strong but rapid aileron disturbance caused a small, fast-settling increase in altitude and a significant drop in speed. This input also induced negative yaw, shown in Fig. 17, and if left without pilot input, the aircraft would continue to travel in a circular path as the roll angle settled back to its trimmed, wings level state. The simulated roll and pitch angle responses, shown in Figs 18 and 19, are significantly more pronounced than their corresponding measured ones to input A2. This is most clearly seen from the roll angle response (Fig. 18). Previous attempts to excite a roll response during the same test flight using smaller amplitude inputs resulted in a negligible roll response.

Overall, the measured aircraft response after input A2 shows much better correspondence to the simulation than the response after A1. It seems the control input frequency has a significant effect on the low frequency response of the aircraft that is not captured with the current simulation parameters. From the wingtip deflection correlation, shown in Fig. 20, it can be seen that the simulation closely predicts initial peak in tip displacement after the aileron input. However, the simulation fails to capture the decaying amplitude of structural response, suggesting that there is a significant source of damping in the experiment that is not adequately modelled in the simulation. Further analysis to determine the vehicle roll response, its relationship to wingtip deflection, and correlations with future flight test measurements are needed to understand this behaviour, and direct measurements of wing shape and wingtip displacement will be required before more detailed correlation can be completed.

The results of the flight tests show that the aircraft does exhibit the expected aeroelastic behaviour, including the capability of developing a large, sustained wingtip displacement during flight, and an unstable dynamic flight mode that can be excited using the aircraft's ailerons. The goal of the next phase of flight tests is to conduct more detailed studies of the in-flight behaviour using the fully instrumented X-HALE Aeroelastic Test Vehicle.

\subsection{Discussion of uncertainty in X-HALE RRV flight tests}

Several sources of uncertainty must be considered in the analysis of the results shown in the previous section. The error inherent in the various sensors as well as uncertainty in the test conditions and post-processing contributed to the overall error in the correlation study. The primary sources of uncertainty in the flight data are described below as well as brief recommendations for future test flights.

As mentioned previously, the aircraft rigid-body and structural response, specifically roll angle, pitch angle, and wing-tip displacement, were not measured directly during the test. This data was estimated from post-processing of the onboard video. The cameras use a fish-eye lens, which captures a field of view of nearly 170 degrees, but also distorts objects near the edges of it. The camera is mounted such that the aircraft is always in the centre of the frame, as exemplified in Fig. 5. However, during very large deformation, the wing can extend into the distorted region. Furthermore, while the images themselves measured 1,920 x 1,080 pixels, the aircraft occupies a 


\section{Table 6 \\ List of measurement sensor accuracies}

$\begin{array}{cc}\text { Sensor } & \text { Measurement accuracy } \\ \text { GPS position } & 2 \cdot 5 \mathrm{~m} \\ \text { GPS speed } & 0 \cdot 1 \mathrm{~ms}^{-1} \\ \text { Aileron angle } & 1 \mathrm{deg} \\ \text { Motor RPM } & 200 \mathrm{rpm}\end{array}$

very small percentage of the overall frame, so a single pixel corresponds to a significant portion of the overall motion of the aircraft within the frame. Thus, the amplitudes of the roll angle, pitch angle, and wingtip displacement estimated from those images have considerable uncertainty on their values.

The finite measurement accuracy of the sensors used in the X-HALE RRV are listed in Table 6. These are also indicated in the plots above as error bars. It is important to note that the actual error in measured speed is augmented by the fact that the aircraft was not flying in a constant plane parallel to the ground. The difference between the aircraft speed and its ground (projected) speed was not accounted for in the accuracy presented in Table 6 or in results above.

Finally, considerable error was introduced into the simulation by the use of parameters that were not measured during flight. Due to malfunctions in the data logging system, the elevator servo commands were not recorded during the test flight, and the simulated elevator deflections were assumed to be equal to the trimmed values. The simulation thrust inputs were also set to their calculated trimmed values. However, during the flight, the motors experienced individual variations in current draw and rpm, which resulted in variations in thrust during the test period. Finally, although the airfield conditions were nearly ideal, the wind speed gradient, temperature variation, and random excitations (e.g., thermals) are experimental conditions that influence the flight results but are not modelled within the simulation and must be considered in the final analysis.

For future flights, the X-HALE Aeroelastic Test Vehicle will be equipped with instrumentation capable of measuring airspeed, angle of attack, sideslip angle, structural deformation, and rigid body motion at multiple locations along the wingspan to gain a more detailed picture of the aeroelastic aircraft response. As with all experiments, sensor accuracy and test conditions will still factor into the uncertainty of the results, but the quality of the collected experimental data is expected to be much better, providing more accurate flight data and better conditions for correlation with the simulated results.

\subsection{CONCLUDING REMARKS}

This paper presented the results from the initial flight tests of the X-HALE Risk Reduction Vehicle, the airframe for an aeroelastic test bed aircraft under development at the University of Michigan. The $6 \mathrm{~m}$ span, very flexible aircraft was designed such that it would exhibit nonlinear aeroelastic and flight dynamic coupled response. The goal of the initial test flights was to assess the X-HALE airframe's handling qualities and aeroelastic response, and verify that the configuration is capable of large deformations during flight. A secondary objective was to use whatever data could be extracted from those flights and correlate it with UM/NAST. To this end, the X-HALE RRV carried a limited sensor payload consisting of an RC-type data acquisition system and onboard cameras to record the aircraft response. 
The expected coupled structural and flight dynamic response was observed during the flight tests with varying degrees of intensity, including large sustained wingtip displacement during flight, and an unstable lateral dynamic mode that can be excited using the aircraft's ailerons. The aircraft was controllable throughout the tests although it presented poor handling qualities. Unfortunately, with the limited instrumentation available on the X-HALE RRV, it is not possible to quantify these effects that were clearly visible from the ground (and in videos that can be found online). Simulations of the aircraft response associated with two different aileron disturbances were conducted using UM/NAST and comparisons with the experimental data were presented. In general, due to the poor quality of the data obtained from these initial flights, limited conclusions can be made regarding the quality of the correlation. However, these results successfully confirmed the design goals and opened the way for the assembly of a new fully-instrumented airframe for aeroelastic flight tests. With the fully-instrumented airframe, high-quality data should be obtained and a more quantifiable correlation study can be conducted to assess the quality of prediction tools.

\section{ACKNOWLEDGEMENTS}

This work has been supported in part by the Air Force Research Laboratory under the Michigan/ AFRL Collaborative Center in Aeronautical Sciences (MACCAS). The technical monitor was Edward Alyanak (AFRL/RZ). Additional funds were also provided by the University of Michigan's Active Aeroelasticity and Structures Research Laboratory. And the first author is supported by the National Science Foundation Graduate Student Research Fellowship under Grant No. DGE 0718128. Finally, the authors would like to thank Keith Shaw (pilot, University of Michigan) and all the University of Michigan students who have been a part of the X-HALE team over the past few years.

\section{REFERENCES}

1. Zerweckh, S.H., von Flotow, A.H. and Murray, J.E. Flight testing a highly flexible aircraft : Case study on the MIT Light Eagle, J Aircr, 1988, 27, (4), pp 342-349.

2. VAN SCHOOR, M.C. and vON FLOTOW, A.H. Aeroelastic characteristics of a highly flexible aircraft, $J$ Aircr, 1990, 27, (10), pp 901-908.

3. Patil, M.J., Hodges, D.H. and CesniK, C.E.S. Nonlinear aeroelasticity analysis of complete aircraft in subsonic flow, J Aircr, 2000, 37, (5), pp 753-760.

4. Patil, M.J., Hodges, D.H. and CesniK, C.E.S. Nonlinear aeroelasticity and flight dynamics of high-altitude long-endurance aircraft, J Aircr, 2001, 38, (1), pp 88-94.

5. PatiL, M.J. and Hodges, D.H. Flight dynamics of highly flexible flying wings, $J$ Aircr, 2006, 43, (6), pp 1790-1799.

6. Chang, C.S., Hodges, D.H. and Patil, M.J. Flight dynamics of highly flexible aircraft, J Aircr, 2008, 45, (2), pp 538-545.

7. CESNIK, C.E.S. and Su, W. Nonlinear aeroelastic modeling and analysis of fully flexible aircraft, 2005, 46th AIAA/ASME/ASCE/AHS/ASC Structures, Structural Dynamics and Materials Conference, Austin, TX, pp 1-27.

8. SheARER, C.M. and CESNIK, C.E.S. Nonlinear flight dynamics of very flexible aircraft, J Aircr, 2007, 44, (5), pp 1528-1545.

9. CESNIK, C.E.S. and BROwn, E.L. Active warping control of a joined-wing airplane configuration, 2003, 44th AIAA/ASME/ASCE/AHS Structures, Structural Dynamics and Materials Conference, Norfolk, VA, USA, pp 1-15.

10. DRELA, M. Integrated simulation model for preliminary aerodynamic, structural, and control-law design of aircraft, 1999, 40th AIAA Structures, Structural Dynamics, and Materials Conference, St Louis, MO, USA, pp 1-14. 
11. Palacios, R., Murua, J. and CooK, R. Structural and aerodynamic models in nonlinear flight dynamics of very flexible aircraft, AIAA J, 2010, 48, (11), pp 2648-2659.

12. Noll, T.E., Brown, J.M., Perez-Davis, M.E., Ishmael, S.D., Tiffany, G.C. and Gaier, M. Investigation of the Helios prototype aircraft mishap, Volume I, January 2004, NASA Mishap Report.

13. TANG, D. and DoweLL, E.H. Experimental and theoretical study on aeroelastic response of high-aspectratio wings, AIAA J, 2001, 39, (8), pp 1439-1441.

14. Su, W., ZhANG, J. and CESNIK, C.E.S. Correlations Between UM/NAST nonlinear aeroelastic simulations and experiments of a slender cantilever wing, 2009, International Forum of Aeroelasticity and Structural Dynamics, Seattle, WA, USA, pp 1-16.

15. Sotoudeh, Z., Hodges, D.H. and Chang, C.-S. Validation studies for aeroelastic trim and stability of highly flexible aircraft, J Aircr, 2010, 47, (4), pp 1240-1247.

16. Cesnik, C.E.S., Senatore, P.J., Su, W., Atkins, E.M. and Shearer, C.M. X-HAlE: A very flexible unmanned aerial vehicle for nonlinear aeroelastic tests, AIAA J, 2012, 50, (12), pp 2820-2833.

17. CeSNIK, C.E.S. and Su, W. Nonlinear aeroelastic simulation of X-HALE: A very flexible UAV, 2011, 49th AIAA Aerospace Sciences Meeting including the New Horizons Forum and Aerospace Exposition Orlando, FL, USA, pp 1-13. 